Portland State University

PDXScholar

\title{
A study of the perceptual parameters of voice in aging females
}

\author{
Barbara Ann Mathers \\ Portland State University
}

Follow this and additional works at: https://pdxscholar.library.pdx.edu/open_access_etds

Part of the Gender, Race, Sexuality, and Ethnicity in Communication Commons, and the Speech Pathology and Audiology Commons

\section{Let us know how access to this document benefits you.}

\section{Recommended Citation}

Mathers, Barbara Ann, "A study of the perceptual parameters of voice in aging females" (1978).

Dissertations and Theses. Paper 2865.

https://doi.org/10.15760/etd.2860

This Thesis is brought to you for free and open access. It has been accepted for inclusion in Dissertations and Theses by an authorized administrator of PDXScholar. Please contact us if we can make this document more accessible: pdxscholar@pdx.edu. 
AN ABSTRACT OF THE THESIS OF Barbara Ann Mathers for the Master of Science in Speech Communication: Emphasis in Speech Pathology/Audiology presented June 6, 1978 .

Title: A Study of the Perceptual Parameters of Voice in Aging Females.

APPROVED BY MEMBERS OF THE THESIS COMMITTEE:

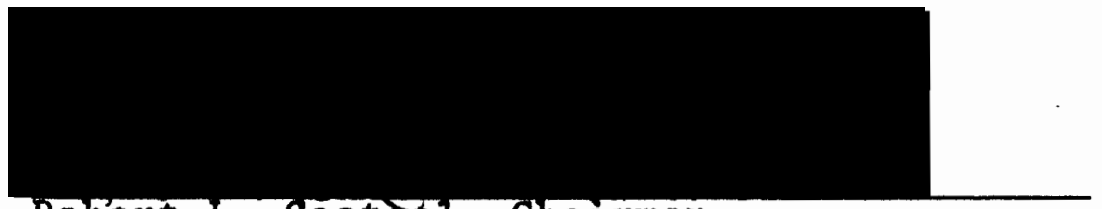

Robert L. easteel, Chairman
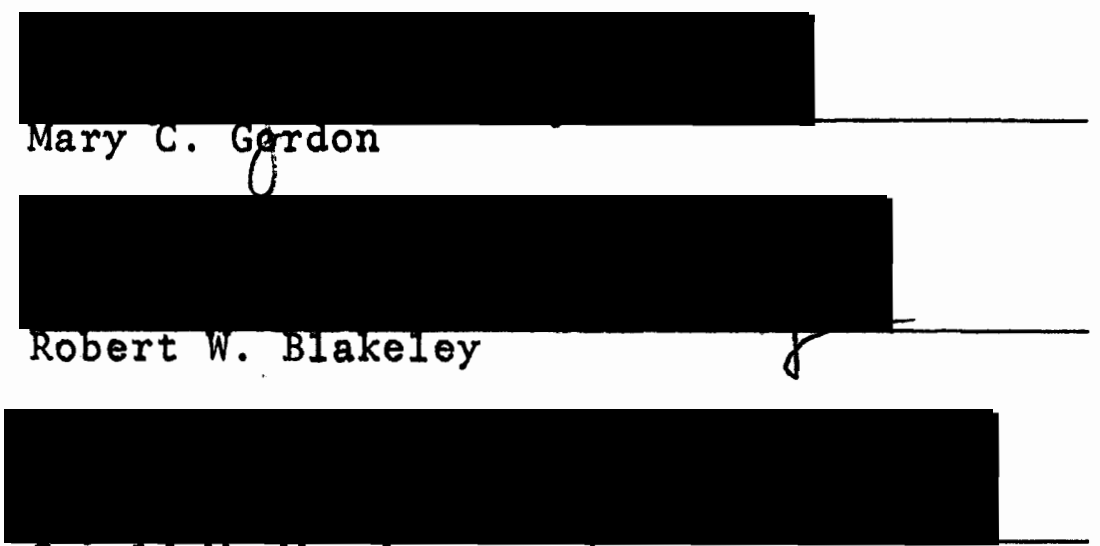

Gerald M. Murch

An interest in understanding the aging processes, as they relate to voice, has prompted research investigating physiological, acoustical, and perceptual attributes of the aging vocal mechanism. Recently, it has been demonstrated that perceptual parameters, in older male voices, differentiate speakers according to age estimations, as deter- 
mined by a group of listeners.

The purpose of this study was to determine the perceptual characteristics of the female voice which are associated with perceived age, as contrasted to chronological age.

The present investigation sought answers to the following questions:

1. By decades, to what degree do selected perceptual parameters characterize the voices of women from 40 to 80 years in percoived age?

2. By decades, to what degree do selected perceptual parameters characterize the voices of women from 40 to 80 years in chronological age?

3. Secondarily, does the inter-judge agreement on age estimation vary with increases in the subjects' chronological ages?

The voices of 60 female subjects, ranging from 40 through 80 years of age, were recorded. In Part I of the study, 11 college students 1 istened to voice samples and estimated the speakers' ages. In Part II, 4 trained judges rated the voices, according to the presence of 18 selected vocal parameters.

For each voice sample, the mean perceived age (PA) and standard deviation were determined, based on the 11 age estimations. The ratings of the vocal parameters were analyzed according to $\mathrm{PA}$ and $\mathrm{CA}$ decade groupings. An analy=

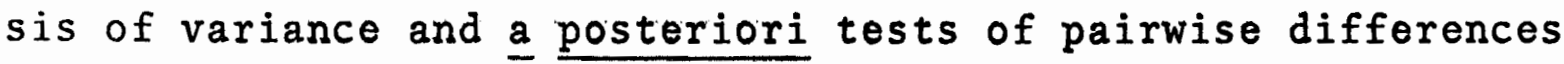


were used to determine the significance of relationships between the perceptual parameter ratings and the PA or CA decades. The relationship between aging and inter-judge agreement on age estimation was assessed using a Pearson $r$ coefficient of correlation.

In general, when classified by $P A$ and $C A$ decades, the voices were normal, with an emphasis on a lack of characteristics which might be age-related. Voice tremor and vocal fry were found to be the primary indicators of perceived and chronological aging, by decade.

Five other parameters, which were statistically shown to relate in some way with $P A$ and CA groups, were as follows: pitch (high), pitch (low), excessive pitch variability, reduced pitch variability, and breathy. Four parameters were characteristic of specific PA decades, only: loudness (soft), imprecise consonants, hypernasal, and hyponasal. The four parameters which were shown to be characteristic of CA decades, only, were fast rate of articulation, slow rate of articulation, laryngeal tension, and hoarseness. For these thirteen parameters, results were interpreted as indicative of inter-individual differences, or as unique to this particular group of women.

The inter-judge agreement on age estimation was not significantly related to chronological aging. This suggests older female voices are not characterized by age-related cues which are more definite than those associated with younger speakers. 
A STUDY OF THE PERCEPTUAL PARAMETERS OF VOICE

IN AGING FEMALES

by

BARBARA ANN MATHERS

A thesis submitted in partial fulfillment of the requirements for the degree of

\author{
MASTER OF SCIENCE \\ in \\ SPEECH COMMUNICATION \\ With emphasis in \\ Speech Pathology/Audiology
}

Portland State University

1978 
TO THE OFFICE OF GRADUATE STUDIES AND RESEARCH:

The members of the Committee approve the thesis of Barbara Ann Mathers presented June 6, 1978 .

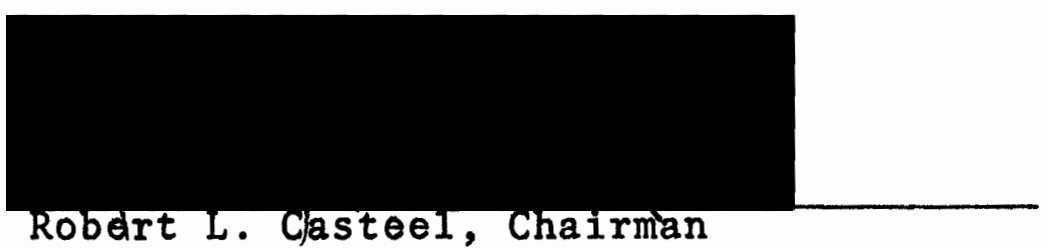

Robert L. C)asteel, Chairman
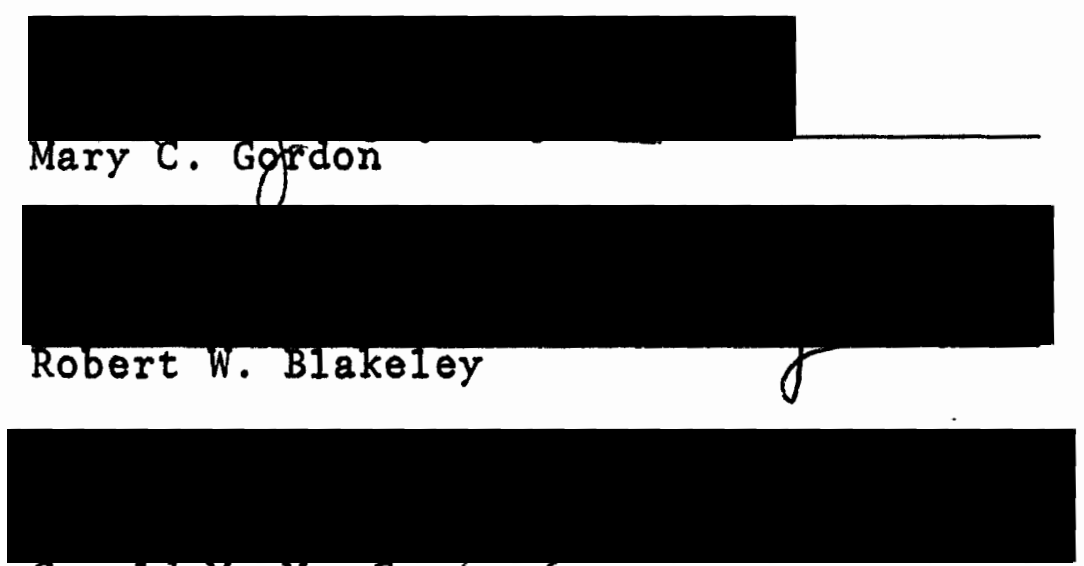

Gerald M. Murch

APPROVED :

Robert W. Vogelsghg, Heady Department of Speech Communication

Stanfey E. Kauch, Jean of Graduate Studies and Research 


\section{ACKNOWLEDGMENTS}

The consistent caring offered by devoted parents is a rare gift. As I express my gratitude for my parents, I wish to acknowledge the support they have given me, throughout my extended formal education. They also have been great teachers, and models, in encouraging a sense of curiosity and an enjoyment of experiences, based on a positive regard for all there is to learn and to appreciate.

Many people helped directly with the research for this thesis: Joan McMahon and Kevin Cole relinquished expected work hours; volunteers from the local P.E.O. chapters, the "Monday Conversation Group," and the administrative offices of Portland State University were among the over one hundred women who served as subjects; Dr. R. E. English, Al Hicks, and Ted Clark assisted in the recording and dubbing of the experimental tapes; eleven students volunteered to serve as "naive listeners"; Mary Jo Bartels, Karen Jenkins, Deon Shope, and Anne Heinrich gave up weekend mornings to serve as trained judges; and Jack Hegrenes and Barbara Stewart served as consultants for the statistical analyses, offering many hours of conference time.

The input from the members of my thesis committee is appreciated. These people provided valuable guidance in writing style, experimental design, and analysis: Mary C. 
Gordon, Robert W. Blakeley, Gorald M. Murch, and Robert L. Castee1, chairman.

I have special memories of working with $\mathrm{Dr} . \mathrm{R}$. L. Casteel, the "non-directive" chairman, who coached me through the workouts of thesis preparation. I consider him to be a master in inspiring students to think independently and to pursue academic interests via research, reading, and discussions. As my advisor and teacher, he has shared an enthusiasm for learning and professional growth. I thank him for his friendship and many contributions to my developing skills as a student, researcher, and clinician. 
TABLE OF CONTENTS

PAGE

ACKNOWLEDGMENTS

LIST OF TABLES .

CHAPTER

I

$$
\text { INTROD }
$$

STATEMENT OF PURPOSE

DEFINITION OF TERMS . . . . . . . .

I I REVIEW OF THE LiteratURE. . . . . . . .

Physiological and Anatomical Changes Associated with Aging . . . . . .

Sex Differences in Physiological

Laryngeal Aging and Subsequent Vocal

Changes . . . . . . . . . . . .

Vocal Changes Associated with Aging 12

III METHODS . . . . . . . . . . . . . 20

SUBJECT SELECTION . . . . . . . . 20

RECORDING PROCEDURE . . . . . . . 21

JUDGING PROCEDURES. . . . . . . . 22

Part I: Age Judgments Made by a

Group of Naive Listeners. . . . .

Part II: Perceptual Analyses by a Group of Trained Listeners. . . .

By Decades, to What Degree Do Selected Perceptual Parameters Char- 
CHAPTER

PAGE

acterize the Voices of Women from 40 to 80 Years in Perceived/

Chronological Ages?

Does the InternJudge Agreement on Age Estimation Vary with Increases in the Subjects' Chronological Ages? .

IV RESULTS AND DISCUSSION. . . . . . . . .

RESULTS . . . . . . . . . . . 28

DISCUSSION.

By Decades, to What Degree Do Selected Perceptual Parameters Characterize the Voices of Women from 40 to 80 Years in Perceived/ Chronological Ages? . . . . . .

Does the Inter-Judge Agreement on Age Estimation Vary with Increases in the Subjects' Chronological Ages? . . . . . . . . . . . .

V SUMMARY AND IMPLICATIONS. . . . . . . .

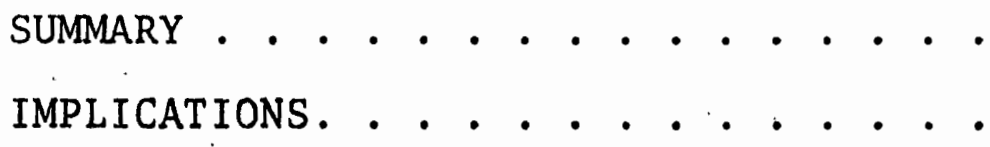

Clinical

Future Research

LIST OF REFERENCES

APPENDIX

A QUESTIONNAIRE USED FOR SUBJECT SELECTION

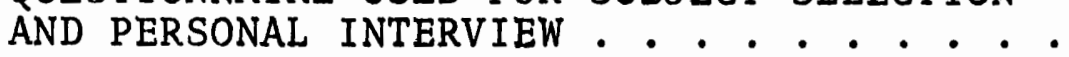

B CHRONOLOGICAL AGE (CA), MEAN PERCEIVED AGE (PA) AND STANDARD DEVIATION OF PERCEIVED AGE (SD) FOR 60 SPEAKERS, EXPRESSED IN YEARS 55

C VOICE PROFILE FORM . . . . . . . . . 56

D DESCRIPTIONS OF THE PERCEPTUAL PARAMETERS AND VOICE RATING SCALE . . . . . . . . . 
vii

APPENDIX

PAGE

E PROCEDURES FOR TRAINING LISTENERS IN

PART II . . . . . . . . . . . . 61

F ANALYSIS OF VARIANCE FOR VOCAL FRY. . . . 64 


\section{LIST OF TABLES}

TABLE

PAGE

I Mean Speaking Frequency and Frequency Deviation of Females: Results from Three Selected Studies . . . . . . . .

I Part I Intra-Judge Reliability Correlation

Coefficients $(r)$. . . . . . . .

II Mean Ratings, $F$ Values, and Pairwise Dif-

ferences for Perceptual Parameters,

According to PA Decades. . . . . . .

IV Mean Ratings, $F$ Values, and Pairwise Dif-

ferences for Perceptual Parameters,

According to CA Decades. . . . . . .

V Appendix B: Chronological Age (CA), Mean

Perceived Age (PA), and Standard Devia-

tion of Perceived Age (SD) for Speakers,

Expressed in Years . . . . . . . . 55

VI Appendix F: Analysis of Variance for Voca1

Fry. . . . . . . . . . . . . . 
CHAPTER I

\section{INTRODUCTION}

During the last half century, medical gains have contributed to the treatment of disorders related to the aging processes. As a result, elderly persons are comprising a larger sector of the population. Concurrently, throughout the habilitative and rehabilitative professions, there has been developing an increased interest in better appreciating and serving the needs of the elderly. Within the field of speech pathology, professionals have been concerned with aging as it relates to communication disorders.

The "worn out" aging voice, which to varying degrees is associated with age related physiological changes, may be a hindrance to effective communication. In some cases, attempts to compensate for structural change may result in augmenting vocal dysfunction. Part of the responsibility for determining whether or not a voice disorder is amenable to treatment rests with speech pathologists specializing in voice. An understanding of the aging of the vocal mechanism seems essential to both the assessment of voice disorders and the development of appropriate intervention strategies. Additionally, a recognition of perceptual parameters normally associated with the aging voice is fundamental to discerning 
what is abnorma1.

In general, research has focused on gaining physiologic and acoustic information concerning voice and chronological aging (Mysak, 1959; McGlone and Hollien, 1963; Ptacek, Sander, Maloney and Jackson, 1966; and Saxman and Burk, 1967). An exception to this trend was a study conducted by Ryan (1971), who investigated the perceptual and acoustic correlates of aging in the male voice. Ryan found a significant relationship between listener estimations of a speaker's age ("perceived age") and perceptual variables, such as voice tremor and air 1oss.

Although several researchers have investigated the aging female voice (McGlone and Hollien, 1963; Ptacek et al., 1966; and Saxman and Burk, 1967), no specific studies regarding the perceptual characteristics have been encountered. Due to the results of Ryan's (1971) investigation of perceptual characteristics found in the voice of aging males, a similar study of the aging female population seemed warranted. Findings based on a male population cannot be generalized to females, since there are numerous sex differences in the aging process and subsequent voice changes (Pressman and Keleman, 1955; Luchsinger and Arnold, 1965; and Segre, 1971).

\section{STATEMENT OF PURPOSE}

The purpose of this study was to determine the perceptual characteristics of the female voice which are associated 
with perceived age, as contrasted with chronological age. The following essential questions were asked:

By decades, to what degree do selected perceptual parameters characterize the voices of women from 40 to 80 years in perceived age?

By decades, to what degree do selected perceptual parameters characterize the voices of women from 40 to 80 years in chronological age?

Secondarily, does the inter-judge agreement on age estimation vary with increases in the subjects' chronological ages?

\section{DEFINITION OF TERMS}

In reviewing the literature, and in discussing the design and results of the present study, the following terms are used. The definitions are provided as a basis for common interpretations. Additionally, they might alert the reader to special meanings authorities have attributed to some of the terminology. Such consideration is warranted, particularly, in the cases where the general construct of "old age" is 1 abeled.

Acoustic level of analysis: "The acoustic level is characterized by physical data: the various properties of sound waves" (Perkins, 1971).

Acoustic parameters of voice: The physical properties inherent in the sound wave itself. These properties "can 
be measured independent of any human observer" (Benes and Pinson, 1963).

Perception: "The conscious mental registration of a sensory stimu1us" (Dorland, 1974).

Perceptual (psychological) parameters of voice: The subjective properties of voice. These properties "are characteristic of sensations evoked in a human 1 istener and cannot be measured without a live listener" (Denes and Pinson, 1963).

Psychological level of analysis: According to Perkins (1971), "Data of the psychological level, to the extent that they can be objectified, are behavioral." This applies to the productive dimensions of the analysis. In terms of reception of the acoustic signal, the dimensions are cognitive (Perkins, 1971).

Senescence: "The process or condition of growing old, especially the condition resulting from the transitions and accumulations of the deleterious aging processes" (Dorland, 1974).

Senility: "O1d age; the physical and mental deterioration associated with old age" (Dorland, 1974).

Terms used by researchers to denote "old age":

"Senile larynx"--in reference to subjects from 60 to 80 years old (Bach, Lederer, and Dinolt, 1941). "Older males"--describing subjects from 65 to 92 years old (Mysak, 1959). 
"Aged women"--describing women 65 to 94 years old (McGlone and Hollien, 1963).

"Elderly"--in reference to people over 60 years old (Lloyd, 1959).

"Geriatric, of advanced age"--over 65 years of age (Ptacek, Sander, Maloney and Jackson, 1966).

"Geriatric"--referring to patients who are 60 years of age, or older (Cooper, 1970). 


\section{CHAPTER II}

\section{REVIEW OF THE LITERATURE}

Physiological and Anatomical Changes

Associated With Aging

It has long been recognized that aging affects structures and systems associated with the production of voice. In 1931, Kofler (cited by Luchsinger and Arnold, 1965) described the progressive calcification and ossification of hyaline laryngeal cartilages; atrophy was noted in laryngeal muscles, connective tissue and mucosal epithelium.

Later investigations have led to a more thorough understanding of the anatomical and physiological changes attributed to aging. Luchsinger and Arnold (1965) focused on reduced hormone production, tissue change and psychological change (due to both reduced brain function and emotional reaction to aging) as they discussed the aging voice. They noted the correlation between vocal senescence and the following structural characteristics of the aged larynx: increasing rigidity of the joints, loss of elasticity of a11 connective tissue, weakness of the laryngeal musculature, and narrowing blood vessels. They emphasized, additionally, the correlation between decreased endocrine function and all signs of aging. 
Segre (1971) considered the circulatory, hormonal, and neuromuscular mechanisms in his description of age associated changes in the larynx. He attributed the physiological aging of the larynx to the same processes that affect the entire organism--"a reduction in enzymatic activity and intra- and extra-cellular dehydration, or in other words, reduction of hydrometabolism."

Terracol and Azimar (cited by Luchsinger and Arnold, 1965) also related the specific changes in the vocal mechanism to general phenomena of aging, noting alterations of anatomic elements and changes in biochemic functions. As they discussed aging and the respiratory system, reduced endocrine function, the central nervous system and biochemistry, they emphasized the complexity of the patterns of growth and system interactions. They, like many others (Luchsinger and Arnold, 1965; Cooper, 1970; Segre, 1971; and Masoro, 1972), noted any investigation or description is further complicated by attempting to distinguish between the physiological and the pathological changes.

At an advanced age, characteristic changes in the appearance of the larynx can be observed, according to Segre (1971), who described the larynx as follows:

At the most advanced age it is usual to find on laryngoscopy a slightly yellowish discoloration of the mucous membrane, atrophy of the lingual tonsil and of the ventricular folds, with a high degree of visibility of the ventricie and of the upper surface of the vocal cords. Frequently, the vacal cords have lost their normal tension, they are 
flaccid, and phonation indicates a fissure in the middle or anterior third of the glottis, with leakage of air.

Segre also referred to aging effects on other mechanisms which are involved in phonation, specifically the resonating chambers, thoracic cage, respiratory system, and the middle or inner ear. A study of vocal senility, he said, should include an examination of these structures, as well as the liver, heart and adrenal cortex.

Other scientists have contributed additional information regarding age-related anatomical and physiological changes in the laryngeal structures. Bach, Lederer, and Dinolt (1941) conducted a detailed study of the senile laryngeal musculature. They examined laryngeal muscles of subjects between 60 and 80 years of age. Their findings suggested the muscular degeneration may be due to insufficient nourishment, resulting from vasomotor change. Pontoppidan and Beecher (1960) demonstrated the increased latency of the protective laryngeal reflexes among those of advanced age. The aging larynx also was described by Zem1in (1968) and Pressman and Keleman (1955), in terms of overall structural growth patterns and subsequent vocal changes. Ossification may begin as early as age 25. Usually by age 65, the calcification or ossification of the laryngeal cartilages is completed--with the exception of the arytenoid apices, vocal processes, corniculate and cuneiform cartilages and the epiglottis, which never ossify. 
According to the authorities cited thus far, it appears certain changes in the vocal mechanism are somewhat predictable, in terms of aging. The reports have been based on clinical observations, dissections of specimens and controlled studies. The structural changes discussed above include calcification or ossification of some of the laryngeal cartilages, atrophy of tissues and muscles, and narrowing blood vesse1s. A consideration of vocal mechanism aging becomes even more complex when considering aging of the respiratory, nervous, circulatory, and endocrine systems, which affect structures. and functions associated with voice production.

Sex Differences in Physiological Laryngeal Aging and Subsequent Vocal Changes

Although all of the above patterns of aging are common to both sexes, certain sex related differences in laryngeal aging have been noted. Pressman and Keleman (1955) stated the calcification in laryngeal cartilages does not develop as early, nor as extensively, in women as compared to men. They stressed, however, there is great variation (among individuals of both sexes) in patterns of speed, age of onset and degree of ossification and calcification. These observations were supported by Segre (1971), who placed age of onset of calcification at about 18 to 20 years of age in men and at age 40 years in women.

The effects of menopause have been studied with varying results. This may be due, in part, to the inevitable diffi- 
culty of separating menopausal symptoms from coincidental pathology, aging, and suggestibility (Neugarten and Kraines, 1967). Luchsinger and Arnold (1965) suggested there may be a lowering of the vocal range and average speaking level. This varies, however, from one woman to another. In some women who experience voice change, the change may be of short duration. Luchsinger and Arnold proposed there may be a relationship between these alterations in voice production and the preponderance of adrenocortical activity and consequential physical virilization. Pressman and Keleman (1955) insisted a "masculinization" of the voice does not occur as a result of menopause. The effects, if any, seem to be limited and variable, with a slight narrowing of the range as the most common result. The quality of the voice may remain as it was until senility.

Another observation of the effects of menopause is offered by Segre (1971). He contended that after menopause, the predominance of androgenous corticoids from the adrenal glands accounts for the voice becoming more masculine. He reported a three to four tone lowering of the female voice, occurring within a period of a few months or years. The larynx was described as becoming more like that of the male skeleton. Interestingly enough, the effects of menopause on the vocal mechanism were classified as characteristic of delayed feminine vocal evolution. Segre then referred to vocal "senility," and not this "delayed vocal change," as 
appearing earlier in men (65-70 years of age) than in women (70-75 years of age).

This distinction between senility and delayed vocal change probably accounts for Segre's being at variance with other authorities on this subject. Luchsinger and Arnold (1965) found vocal involution in males differed from that in females, with the male voice being affected later, less extensively and more slowly. Supposedly, this is due to the gradual subsiding of male hormone production after age 60. In females, on the other hand, menopause occurs during middle age and lasts for a shorter period of time ( 1 to 2 years). Pressman and Keleman (1955) also described the normal adult voice as being "preserved" longer in males than in females.

As suggested throughout these reports, physiological changes related to the presence of certain hormones account for sex specific changes in laryngeal aging, and ultimately in vocal production. The onset and degree of ossification and calcification also appear to be sex related, with the male larynx being affected earlier and more extensively. While underscoring such sex-associated differences, most of the discussions referred to above included statements emphasizing inter-individual differences in growth patterns. Such differences may partially explain discrepancies among sources describing the age-related changes in vocal production. 
Vocal Changes Associated With Aging

Descriptions of vocal involution vary in the specification and range of age groups considered, the differentiating between sexes, the methods of substantiating claims, and the relating of changes to the aging processes discussed previously.

After stating vocal senescence begins after age 60 in males and around age 50 in females, Luchsinger and Arnold (1965) described some of the characteristic voice changes. A reduced vocal range is attributed to a loss of high tones. This range may shift toward lower frequencies if the vocal folds thicken, or in cases of predominant atrophic changes within the vocal folds, a shift to higher pitches may occur (due to the less massive vibrating structure). Reduced vocal intensity, limited ability to prolong vocal performances, and loss of singing ability, in terms of maintaining pitch level, are noted also. Reduced vital capacity results in lessened power of phonic expiration. Depending on which organic changes predominate, the voice is characteristically "husky and muffled" or "thin and sharp" in timbre, "rough and tremulous" in overall sound, and "wobbling" due to irregular expiration, according to Luchsinger and Arnold.

Segre (1971) included vocal fatigue and hoarseness in his description of the senile voice. He listed other modifications as follows: a movement in pitch toward the higher range; a reduction in vocal intensity (due to reduced expira- 
tory breath, amplitude of vocal fold vibration and resonator flexibility); lack of continuity of pressure and speed in the air stream, resulting in tremulous voice; occasional monotonous voice, or frequent variation toward upper registers when emotional; and a voice which is "opaque and poor in harmonics," due to reduced and uncoordinated action of the supraglottic resonators because of muscular atrophy and loss of mucosal sensitivity.

Sheridan (1976) and Cooper (1970) referred to clinical evidence as they similarly described the voice in geriatric patients--generally persons of 60 years and over. In this sample, they have observed reduced volume, hoarseness, distorted articulation, and habitual use of a lower than optimum pitch. Both authors noted the variability of the effects of aging. They emphasized vocal misuse is often responsible for changes which are usually attributed to aging.

Controlled studies of voice in aging persons have related the physiological and socio-emotional changes to acoustic measurements. Mysak (1959) found increases in the median fundamental frequency and pitch variability were significantly related to increased age in males. A general trend toward reduced rate in words per minute was noted also, although the correlation was not statistically significant.

McGlone and Hollien (1963) conducted a study, similar to Mysak's (1959), in which they investigated the vocal characteristics of aged women. They compared their data to the 
results of Linke's (1953) study of pitch characteristics in younger women. McGlone and Hollien found no significant differences between the speaking pitch levels in young women as compared to those in older women. Their results indicated a slight tendency toward a reduction in pitch variability and range with advancing age in females.

The same data was useful in determining the prevalence of the "senile voice." This term was used by Bach, Lederer, and Dinolt (1941) in describing characteristic changes in the voice associated with degeneration of laryngeal musculature. They were referring to "changes in pitch that render the voice monotonous, flat and occasionally shrill in older people," as described by McGlone and Hollien (1963, p. 164). Because no evidence of the "senile voice" was found in the McGlone and Hollien study, the authors suggested the high criteria for selecting healthy subjects may have prevented gaining information representative of the aging population. In addition, no data were available for middle-aged women. Thus, concluding speaking pitch level and pitch variability change little with advancing age, may have been somewhat unfounded.

Obtaining data for the speaking frequency of middle-aged women was the focus of a study by Saxman and Burk (1967). Their results suggested a decrease in the frequency level of voice as a woman passes from young adulthood through middle age, with a rise in frequency to the former level during old 
age. The authors observed this trend by comparing their findings with those of other reported research. The results of three of the studies compared by Saxman and Burk, are reported in Table I. Saxman and Burk pointed out the need for further study. Limited numbers of subjects, as we11 as procedural differences, may have biased the results.

Changes associated with aging may be most obvious when the system is subjected to stress, according to Masoro (1972). Masoro described the aging physiological system as one which when challenged, shows a reduced ability to return to the normal level of functioning. Ptacek et a1. (1966) suggested the contradictory results of the studies discussed above, might be attributable to a lack of attention to this stress factor. They compared the performance of younger adult (under age 40) and geriatric (over age 65) subjects of both sexes, testing the limits of the speech related functioning

\section{TABLE I}

MEAN SPEAKING FREQUENCY AND FREQUENCY DEVIATION OF FEMALES RESULTS FROM THREE SELECTED STUDIES

\begin{tabular}{lrrrr}
\hline \hline Investigators & $\mathrm{N}$ & Age of Subjects & $\begin{array}{c}\text { Mean Fre- } \\
\text { quency (Hz) }\end{array}$ & $\begin{array}{c}\text { S.D. } \\
\text { (tones) }\end{array}$ \\
\hline Linke (1953) & 27 & "Young adult" & 199.8 & 1.52 \\
& & $30-40$ & 196.3 & 1.23 \\
Saxman and Burk & 9 & $40-50$ & 188.6 & 1.38 \\
$\quad(1967)$ & 9 & & & \\
McGlone and & 10 & 72 (mean age) & 199.6 & 1.48 \\
Hollien (1963) & 10 & 85 (mean age) & 199.8 & 1.35 \\
\hline
\end{tabular}


of the respiratory, phonatory, and articulatory mechanisms. The geriatric subjects showed significantly reduced performances on the measurements of maximum forced pitch range, diadochokineses, maximum vowel intensity, maximum vowel duration, maximum intraoral breath pressure, and vital capacity. In discussing the results, the authors related the speech performance differences to underlying physiological alterations as follows: calcification and reduced muscle/ cartilage elasticity is associated with reduced range; reduced vital capacity and maximum intraoral pressure reflect decreased respiratory muscle power; and degenerative changes in 1aryngeal muscles interacting with respiratory muscles may account for the reduction in maximum vowel duration and vowel intensity performance levels.

In a longitudinal study of six subjects $(4$ males and 2 females), Endres, Bambach, and Flosser (1971) analyzed speech samples taken over a 13 to 15 year period. They evaluated the formant structure, mean pitch frequency (the maximum value of the statistical distribution curve representing fundamental frequency), and variability of fundamental frequency. Although only the first recording ages were given for the youngest male (42 years old) and youngest female (29 years o1d), findings seem noteworthy in terms of the present study. In all cases, the formant center frequencies were found to decrease with increasing age. The authors linked this to the enlargement of the supraglottic tract, which 
results from involution of the "Waldeyer's tonsilar ring" (the palatine tonsils, lingual tonsils, pharyngeal tonsils, gray columns and lymph glands) and the slackening of laryngeal muscles and passive terminations. Stiffening of laryngeal articulations, ossification of laryngeal hyaline cartilage and hypotony of the laryngeal muscles were related to aging and consequential decreased range of speech volume. The authors stated the lowering of pitch frequency, as subjects increased in age, may be attributed to reduced elasticity of the vocal folds and the gathering of lipoid substances around the muscular fibrils of the vocal cords. Reduced range of pitch variation was observed, a1so, in all of the subjects.

Ryan (1971) investigated the voice in aging males to determine which perceptual and acoustic characteristics were predictors of perceived age. The investigation of the perceptual parameters of the aging voice proceeded according to the theory that chronological age might not be as relevant as perceived age, in studying changes in voice. This viewpoint was supported by Segre (1971) who contended the voice mirrors hormonal and collagenic age, moreso than chronological age. Pressman and Keleman (1955) and Greene (1967) also noted voice change in the aging is related, not to chronological age, as much as it is to physiological growth patterns. In order to better understand those voice parameters which listeners associate with aging, Ryan based his analyses of 
perceptual judgments on the "age of the voice" as determined by 1 isteners, or the "perceived age."

The notion that judges could make reliable estimates of age was first reported by Ptacek and Sander (1966). They determined judges could differentiate between young (under age 35 ) and old (over 65 years) subjects when listening to taped speech samples. Shipp and Hollien (1969) later investigated the ability of listeners to determine the ages of 175 male speakers, ranging from 20 to 89 years of age. They found age to be identifiable on the basis of voice samples alone--with a correlation value of +0.88 obtained when mean age estimations were correlated with the speakers' chronologic ages. Both studies led Ryan to infer, "the speech signal being processed contains information used by the listener in making these age determinations."

In his study, Ryan (1971) used the age estimates of 80 male speakers, from 40 to 80 years of age. These estimates were made by 20 untrained listeners. In each of 40 cases where there was a high listener agreement as to the age of the speaker, the recording was used for further analysis. Two groups of trained judges listened to the selected recordings, in order to indicate perceptual characteristics of the voices. The recordings were subjected also to five acoustic measurements. Upon assessing the significance of the variables in predicting perceived age, five perceptual voice characteristics were found to be strong age predictors: 
voice tremor, laryngeal tension, air 1oss, imprecise consonants, and slow rate of articulation.

Ryan's data is applicable only to the male population; as noted earlier, sexual differences in aging and voice characteristics preclude generalizing to the female population. Investigations, specific to the female population, must be conducted in order to understand the relationship between the perceived age of the speaker and characteristic parameters in women's voices. 
CHAPTER III

\author{
METHODS
}

\title{
SUBJECT SELECTION
}

Subjects were recruited by contacting members of women's social organizations and employees in the administrative offices of Portland State University. Sixty volunteer females were selected as subjects. Chronological ages ranged from 40 through 80 years, with 15 subjects in each decade. Another group of 20 volunteers, with 5 subjects in each decade, provided voice samples used in training the judges, in Part II of the present study. Each subject completed a questionnaire (Appendix A). The questions were designed to elicit information regarding vocal training and physiological conditions which might affect voice production. Brief, personal interviews, regarding responses to the questionnaire, were conducted by the author. The criteria for being included in the study, similar to those outlined by Ryan (1971), were as follows :

1. The subject had a pure tone average (the average of the thresholds at $500,1 \mathrm{~K}$ and $2 \mathrm{~K} \mathrm{~Hz}$ ) of at least $30 \mathrm{~dB}$ (ISO) in the better ear. A calibrated Be1tone 15C Audiometer was used to assess each individual's hearing acuity. 
2. The subject did not demonstrate non-voice speech characteristics which might significantly distract a listener's attention from the voice analysis task. For example, potential subjects who demonstrated articulatory disorders or foreign accents were not included in the study. These judgments were made by the author during the personal interviews.

3. The subject had no history of formal voice or speech training.

4. To her knowledge, the subject had never experienced pathological conditions which would affect speech or voice, e.g., cerebrovascular lesion and Parkinson's syndrome.

\section{RECORDING PROCEDURE}

Recording sessions were conducted in the Portland State University audiology suite, a sound treated acoustic environment. Voice samples were recorded on Maxel1 35-90 tapes, at a tape speed of 7.5 inches per second and record level of 7 . Recording equipment consisted of an Ampex AG-500 portable tape recorder which was coupled to an Electro-Voice $635 \mathrm{~A}$ Dynamic microphone. The microphone was attached to a stand and placed so there was, approximately, an 8 inch mouth-tomicrophone distance. Each subject was instructed to read the first paragraph of the "Rainbow Passage" (Fairbanks, 
1960). The paragraph was printed in oversized type to accommodate subjects who might have slightly reduced visual acuity. The standard instructions read to each subject were as follows:

Please familiarize yourself with this passage by reading it aloud two times. When you have finished practicing, 10ok at me. I will point to you to signal when you should begin the third reading. A recording will be made of this third reading. Read the paragraph as though you were reading it to a group of ten people. please read without stopping, even if you miss a word. Do you have any questions?

\section{JUDGING PROCEDURES}

Part I: Age Judgments Made by a Group of Naive Listeners

Tape Preparation for the Age Estimation Task. The Part I experimental tape was produced by dubbing from the master copies made in the original recording sessions. Two Sony 105 portable tape recorders were used in the dubbing process. The Part I tape consisted of random ordered voice samples, the fourth and fifth sentences of the "Rainbow Passage," of al1 60 subjects. This method of re-recording sentences was first reported by Shipp and Hollien (1969) and later was adhered to by Ryan (1971).

Age Estimation Sessions. A group of 11 untrained listeners, young adult college students, 1istened to the 60 voice samples. Two listening sessions were held in order to accommodate all of the 1 isteners. The listeners were instructed as follows: 
The recordings you will hear are of female speakers, ranging in age from 40 to 80 years. After each speaker has finished reading the two sentences, there will be a 5 second pause. Make an estimation of the speaker's age, to the nearest year. Record the estimation on the form wich I have given you.

A 3 minute break was given, after the 25 th sample, so fatigue effects would be minimized. The recordings were played through a high fidelity Ampex AG 500 and Ampex Pre-Amplifier system in a college classroom.

Following the presentation of the 60 samples and another 3 minute break, 10 of the recordings, randomly selected and randomly ordered, were presented for re-estimation of the speakers' ages. The listeners were not informed they had already judged the final 10 recordings, since this was a test for intra-judge reliability.

Individual correlation coefficients were obtained by comparing initial judgments to the second age estimates. The resulting coefficients ranged from $r=0.22$ to $r=0.90$, and are displayed in Table II. The inter-judge agreement in age estimation was measured by determining the standard deviation from the mean perceived age. The 60 standard deviations ranged from 2.04 to 10.40 , with a mean S.D. of 6.52 years. The results are shown in Appendix B.

Part II: Perceptual Analyses by a Group of Trained Listeners

Tape and Listener Preparation for Perceptual Analyses. The original recordings of all speakers reading the "Rainbow Passage" paragraph were randomized and re-recorded on a 
TABLE II

PART I INTRA-JUDGE RELIABILITY CORRELATION COEFFICIENTS $(r)$

\begin{tabular}{cccc}
\hline Listener & $r=$ & Listener & $r=$ \\
\hline 1 & 0.57 & 7 & 0.62 \\
2 & 0.83 & 8 & 0.52 \\
3 & 0.56 & 9 & 0.74 \\
4 & 0.69 & 10 & 0.74 \\
5 & 0.80 & 11 & 0.22 \\
6 & 0.90 & & \\
\hline
\end{tabular}

second experimental tape. Each recording was dubbed twice (in succession), so the listeners would be presented with a voice sample of sufficient duration for perceptual analysis. This method of tape preparation was first described and used by Ryan (1971).

Four female graduate students comprised the group of "trained listeners." A11 of them had been instructed in the use of the St. Louis Jewish Hospital Voice Profile (Wilson, 1971) and had participated in the diagnosis and management of at least two clients in the Portland State University Voice Clinic. These listeners participated in two training sessions, for a total of three hours. They were instructed in the use of the voice profile developed for the purposes of this investigation (Appendix C). See Appendix D for descriptions of the vocal parameters to be judged and the 
voice rating scale. In Appendix E, the training session procedures are described.

Judging Sessions. In order to minimize listener fatigue, the tapes were analyzed in two separate two hour sessions. They were played through the Ampex Pre-Amplifier system in a college classroom. Recordings were presented in groups of 10 , followed by a 5 minute break. The 1isteners were instructed to judge each speaker's voice according to the nature of specific vocal parameters, as described on the rating guidelines sheet (Appendix D). They recorded their judgments on the voice profile forms (Appendix C).

Ten of the recordings were randomly selected for rejudgment. These recordings were presented on the second day, following the rating of the 60 original random ordered voice samples. The listeners were not told they previously had judged the final 10 voices.

For each judge, a percentage of internal agreement was calculated, based on initial and second ratings of the 10 voices. The individual percentages of agreement were as follows: Judge 1--0.83; Judge 2--0.90; Judge 3--0.83; Judge 4-0.84 . The overall intra-judge agreement was 0.85 . The interjudge percentage of agreement was 0.90 , overall.

\section{DATA ANALYSIS}

By Decades, To What Degree Do Selected Perceptual Parameters Characterize the Voices of Women from 40 to 80 Years In Perceived/Chronological Ages?

In order to answer the primary questions the 60 subjects 
were grouped according to perceived age (PA) and chronological age (CA) decades. The distribution of subjects by PA decade was as follows: Decade I (40-49 years PA)--9 subjects; Decade II (50-59 years PA)--20 subjects; Decade III (60-69 years PA)--25 subjects; Decade IV (70-79 years PA)-6 subjects. When the subjects were grouped according to chronological ages, there were 15 subjects in each CA decade. The decision was made to analyze the data according to the speakers' chronological ages, in addition to perceived ages, in order to have a "reality check."

For each parameter, an analysis of variance, as described by Winer (1971), was used to determine the significance of the relationship between the judges' mean ratings and $\mathrm{PA}$ or $\mathrm{CA}$ decades. This statistical procedure involved the calculation of an $F$ ratio, and a comparison of this value to a critical $F$ value, for both $p<.05$ and $p<.01$. An example of this procedure is displayed in Appendix F. In each case where the $F$ ratio was statistically significant, an a posteriori test was used to determine more specifically where the indicated significance lay. The selected method of testing differences among means was the Tukey procedure (Kirk, 1968).

Does the Inter-Judge Agreement on Age Estimation Vary with Increases in the Subjects Chronological Ages?

A Pearson $r$ coefficient of correlation was calculated to determine the significance of the inverse relationship 
between an increase in the subjects' chronological ages and a decrease in the size of the standard deviations for the mean perceived ages. 
CHAPTER IV

\section{RESULTS AND DISCUSSION}

The results of the present study are reported in two parts. Data relevant to answering the primary questions are presented first. This is followed by a report of the results pertinent to the secondary question. The interpretations of these results are discussed in a separate subsection of the chapter.

\section{RESULTS}

By Decades, To What Degree Do Selected Perceptual

Parameters Characterize the Voices of Women from 40 to 80 Years In Perceived/Chronological Ages?

Statistical analysis revealed significant relationships between age and the ratings for fifteen of the nineteen perceptual parameters. The fifteen parameters which were significantly age-related were as follows: vocal fry, voice tremor, pitch (high), pitch (low), excessive pitch variability, reduced pitch variability, breathy, loudness (soft), imprecise consonants, hypernasal, hyponasal, fast rate of articulation, slow rate of articulation, laryngeal tension, and hoarseness. One of the parameters, laryngeal tension, was analyzed by combining the ratings for harshness, hoarseness, and stridency. For each of the fifteen parameters, 
the results of the analysis of variance, according to perceived and chronological age decades, are reported below. For all of the parameters rated, the mean ratings by decade, overall F values, and significant pairwise differences are displayed in Tables III and IV, according to perceived age (PA) and chronological age (CA) groupings, respectively. Analysis of Ratings According to Perceived Age Rela-

tionships. The following eight perceptual parameters were found to be associated with PA beyond the significance level of $\mathrm{p}<.01$ : vocal fry, voice tremor, pitch (high), pitch (low), excessive pitch variability, reduced pitch variability, breathy and loudness (soft). Statistical analysis yielded significant $F$ values, at the $p<.05$ level, for the PA groupings of ratings and three parameters: imprecise consonants, hypernasal, and hyponasal.

Pairwise differences were computed for the possible six comparisons of decades, for each of the above parameters. As shown in Table III, the mean ratings for vocal fry were significantly different for three comparisons. The mean rating for the fourth PA decade group was higher than mean ratings for the first and second PA decade groups: IV> I $(\mathrm{p}<.01)$, IV > II $(\mathrm{p}<.01)$. The mean rating for the third PA decade was also higher than that of the first: III>I $(p<$ $.01)$. The significance of PA relationships with voice tremor lay in comparing the fourth decade mean to mean ratings of the other three decades: IV > I, IV >II, and IV>III; a11 


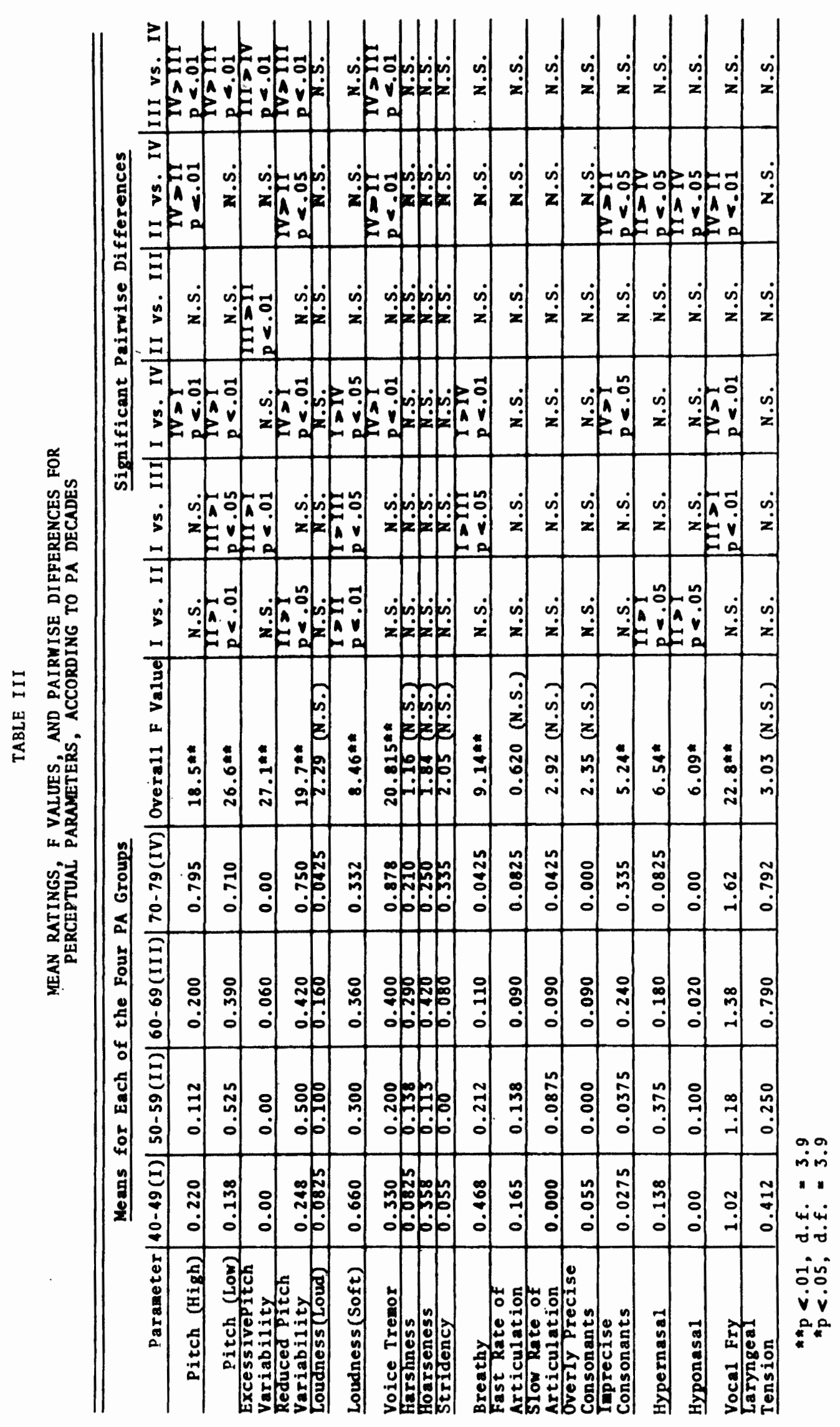




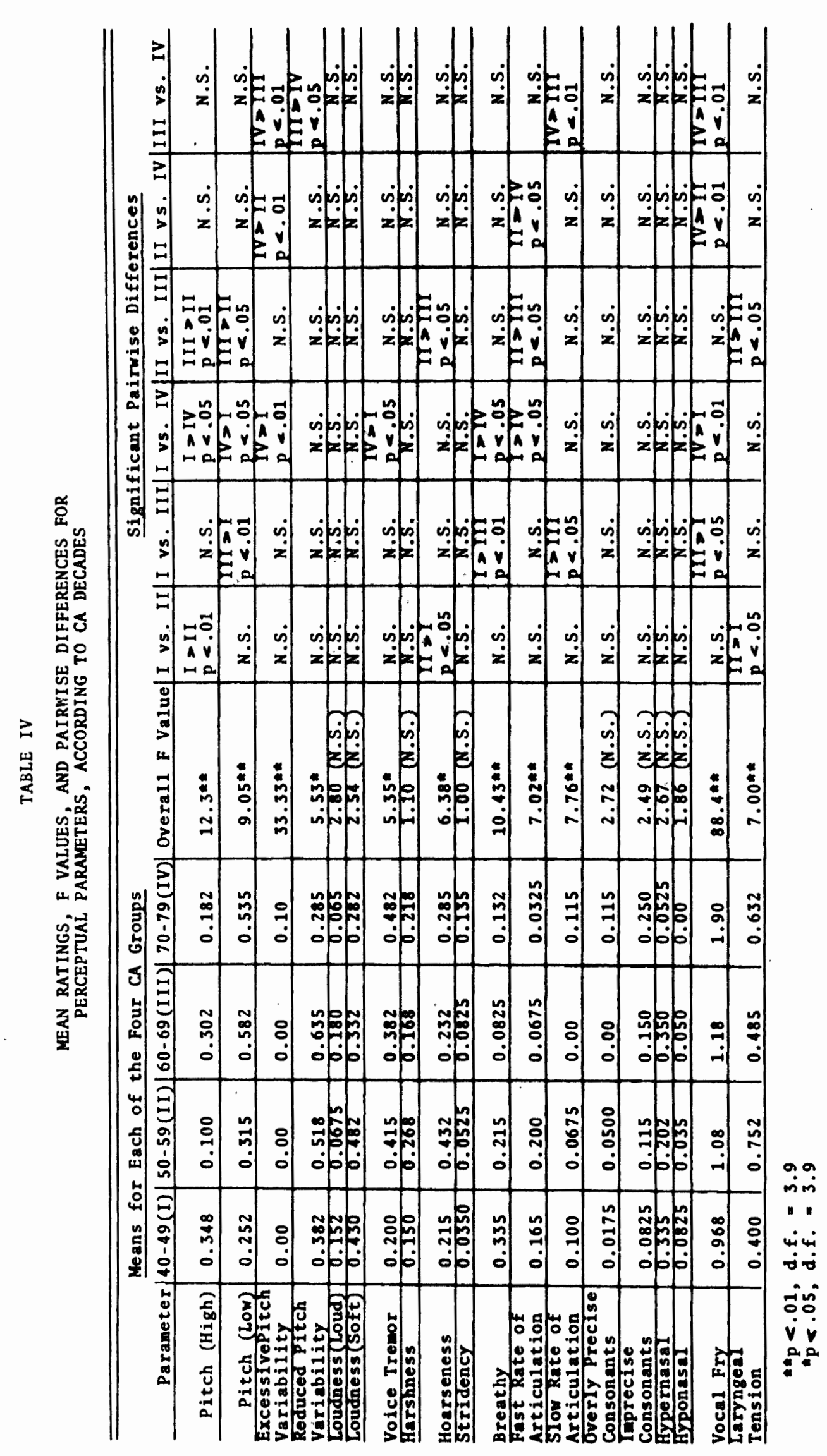


differences were significant at $p<.01$.

Comparisons of the mean ratings attributed to pitch parameters revealed a variety of PA associated relationships. Pitch (high) mean ratings varied significant1y with $P A$ as fol1ows: IV > I, IV > II, IV > III; aII differences were significant at $\mathrm{p}<.01$. Comparisons of PA decade mean ratings for pitch (low) yielded the following: II $=I \quad(p<.01)$, I I I $>$ I $(p<.05)$, IV $>$ I $(p<.01)$, and IV $>$ I II $(p<.01)$. For excessive pitch variability, the third decade mean was higher than the means for the other three decades; in all three cases, the level of significance was $p<.01$. Analysis of PA related reduced pitch variability also yielded significant differences: II $>$ I $(p<.05)$, IV > I $(p<.01)$, IV $>$ I I $(p<.05)$, and IV $>$ III $(p<.01)$.

The significant pairwise differences for loudness (soft) and breathy ratings were similar. The mean loudness (soft) rating of the first PA decade was greater than the means of the other three PA decades: I > I $(p<.01)$, I $>$ I I I $(\mathrm{p}<.05)$, I > IV $(\mathrm{p}<.05)$. The mean ratings of breathy were significantly age-related in two cases: I $>$ III $(p<.05)$ and I $>$ IV $(\mathrm{p}<.01)$.

The remaining parameters, which were age-related, were imprecise consonants, hypernasal, and hyponasal. The mean for ratings on imprecise consonants was significantly greater in the fourth PA decade, when compared to both the first and second PA decade means $(p<.05)$. For hypernasal and hypo- 
nasal mean ratings, the following differences were indicated by the a posteriori analyses: II $>I(p<.05)$ and $I I>I V$ $(\mathrm{p}<.05)$.

Analysis of Ratings According to Chronological Age Relationships. Statistical analysis indicated the following eight perceptual parameters were related to CA beyond the significance level of $\mathrm{p}<.01$ : vocal fry, pitch (high), pitch (low), excessive pitch variability, breathy, fast rate of articulation, slow rate of articulation, and laryngeal tension. The analysis of variance yielded significant $F$ values, at the level of $p<.05$, for three parameters: voice tremor, reduced pitch variability, and hoarseness.

The a posteriori test of computing pairwise differences between decades was performed for each parameter listed above. The mean ratings for vocal fry wore significantly different $(p<.01)$ for four comparisons: III > I, IV > II, IV > III. Voice tremor was significantly associated with CA when comparing mean ratings for the fourth and first decades: IV $>I$ $(p<.05)$.

The analyses of ratings for parameters involving pitch indicated various $C A$ associated relationships. The mean ratings for pitch (high) were associated with CA decades, in the following manner: I $>$ II $(p<.01)$, I $>$ IV $(p<.05)$, III $>$ II $(p<.01)$. An increase in the mean ratings of pitch (low) was associated with increase in age, according to $\mathrm{CA}$. decades: III $>$ I $(p<.01)$, IV $>$ I $(p<.05)$, III $>$ II $(p<.05)$. 
Excessive pitch variability was rated significantly higher for the fourth decade in comparison to the other three: IV > I, IV > I I, IV > III; alI differences were significant at $\mathrm{p}<.01$. Reduced pitch variability was related to chronological age, only when comparing the third and fourth CA decades: III $>$ IV $(\mathrm{p}<.05)$.

For both breathiness and fast rate of articulation, inverse relationships with chronological aging were indicated. The mean ratings of breathy were related to $\mathrm{CA}$ the same way they were related to PA: I >III $(p<.01)$ and I $>$ IV $(p<.05)$. Fast rate of articulation mean ratings were associated with CA decades as follows: I $>$ IV $(p<.05)$, II $>$ III $(p<.05)$, and II $>$ IV $(p<.05)$. The significance attributed to relationships between $\mathrm{CA}$ and slow rate of articulation was due to the absence of ratings beyond " $0, "$ in the third decade: I $>$ III $(p<.05)$ and IV $>$ III $(p<.01)$.

The relationships between $C A$ and mean ratings for laryngeal tension and hoarseness were identical: II > I $(\mathrm{p}<.05)$ and II $>$ III $(\mathrm{p}<.05)$.

Parameters Not Related to PA or CA Decades. For the remaining four parameters, the analyses of variance of both $\mathrm{PA}$ and $\mathrm{CA}$ related ratings yielded $\mathrm{F}$ values which were not statistically significant. The perceptual parameters, so identified, were as follows: loudness (loud), harshness, stridency, and overly precise consonants. 
Does the Inter-Judge Agreement on Age Estimation Vary with Increases in the Subjects ${ }^{\top}$ Chronological Ages?

The above question refers to the age estimations made by 11 naive listeners. Inter-judge agreement, as indicated by the standard deviations from the mean perceived ages, is displayed in Appendix B. A Pearson $r$ coefficient of correlation was calculated to determine the significance of the inverse relationship between aging and the magnitude of the standard deviation of the mean perceived ages. This statistical procedure yielded a correlation coefficient of $r=-0.15$, which is not significant (Wa1ker, 1969). According to Guilford (1956), the strength of the inverse relationship can be described as "slight" or "almost negligible."

\section{DISCUSSION}

By Decades, To What Degree Do Selected Perceptual Parameters Characterize the Voices of Women from 40 to 80 Years In Perceived/Chronological Ages?

In general, the results indicate that female voices, classified by perceived and chronological age decades, are mixed and varied, with an emphasis on a lack of characteristics which might serve as perceptual cues in identifying a speaker's age. With the exception of vocal fry, the most prevalent parameter rating was " 0 ," or "not characteristic of the voice being judged." A rating of " 0 " means the voice was considered as normal, with respect to the particular parameter or parameters. 
It can be said, for the most part, an overwhelming number of speakers at all ages demonstrated normal voices. For all but three parameters, more than half of the speakers were rated as "0," by all four trained judges. The three exceptions, and the corresponding proportion of subjects rated as "0" by all. judges, were as follows: vocal fry $(8 / 60)$, voice tremor $(30 / 60)$, and laryngeal tension (22/60). Although other parameters were shown to be statistically related to specific decades, in several cases the levels of significance were determined by ratings of only a few speakers. The most extreme example is in the case of excessive pitch variability. For both PA and CA groupings, the analyses of variance yielded $F$ values well beyond the $p<.01$ level of significance, even though only two speakers received ratings beyond "0."

It should be emphasized that all the subjects who participated in this study met the criteria outlined in Chapter III. This method of selection excluded women who had known physiological disorders which might affect their voices. It is possible those voice characteristics normally associated with aging are, in some cases, related to physiological pathologies. This same concern was stated by McGlone and Hollien (1963) when they found, in females, pitch level does not vary significantly with increasing age. In the present study, the lack of definite associations between older age groups and the presence of identifying vocal parameters, may 
be attributed, in part, to the selection of active, healthy subjects. Based on this assumption, the findings indicate that active, healthy females, from 40 to 80 years of age, continue to demonstrate normal vocal characteristics while reading.

The results clearly indicated relationships between aging and two parameters, voice tremor and vocal fry. Such findings merit special attention for several reasons, which will be discussed in the following paragraphs. First of al1, it seems important that the relationships were found to occur for both PA and CA voice groupings. Secondly, the manner in which the voice tremor is associated with aging differs from that of vocal fry. Finally, both relationships can be explained in terms of what is known about the aging process and physiological changes.

The first issue raised above, points to the value of analyzing the data in terms of both perceived and chronological age designations. Because there was a moderate correlation $(r=.60)$ between the perceived and chronological ages, the relationships between ratings of vocal parameters and $\mathrm{PA}$ groupings are worthy of consideration. However, because of the wide range of variability in age estimation results, the PA evidence, for age-associated vocal characteristics, seems weak when standing alone. When the PA results are supported by CA findings, stronger statements can be made. The "reality. check" with CA data confirms the existence of the relationship. 
The significant associations with the perceived ages suggest the likelihood these cues are being used in making age estimations. The higher significance level of the voice tremor PA findings, in comparison to the related CA level of significance, leads to further speculation. Possibly the listeners associate voice tremor with aging to a degree not indicated by "reality." This possibility is supported by the $\underline{a}$ posteriori analysis which revealed voice tremor characterized speakers in the fourth PA decade, to a greater degree than in the other three decades. A significant difference between $C A$ decade ratings of voice tremor was indicated only when comparing the fourth and first decades (IV $>$ I).

The difference in patterns of relationships emphasizes the value of rating the degree to which a parameter characterizes a voice. For voice tremor, the judgments, indicating the age-associated presence of this parameter, increased in frequency alone. Only one rating above "mild" was assigned to a voice sample. On the other hand, the significance attributed to vocal fry rests primarily on the degree of its presence. It might be that if listeners had been asked to judge only the presence or absence of the parameter, the power of its contribution to estimating age would have gone unnoticed. This is also true for the strength of its relationship with chronological aging.

Finally, the anatomical and physiological changes; which are known to be associated with aging, can explain the 
increased perception of both voice tremor and vocal fry. Voice tremor is usually symptomatic of neurological dysfunction, according to Boone (1977). Additionally, neuromuscular changes and irregular expiration, conducive to the production of voice tremor, are considered as part of the expected aging process (Luchsinger and Arnold, 1965; Segre, 1971). The vocal fry could be attributed to lack of pressure in the air stream (Segre, 1971) and laryngeal muscular degeneration (Bach, Lederer and Dinolt, 1941; Segre, 1971) which are reportedly associated with aging processes. Although these parameters are differentially perceived and labeled, the relevant anatomical changes and physiological events appear to be similar and interacting.

The results of analyzing ratings for parameters related to pitch revealed an assortment of associations between PA and $\mathrm{CA}$ decades and the particular parameters. When considering PA groupings of speakers, pitch (high), pitch (1ow), and reduced pitch variability were statistically shown as related to increased age. Excessive pitch variability was related particularly to the third PA decade. The CA groupings of speakers showed different patterns. Excessive pitch variability and pitch (low) were shown to be related to aging. Reduced pitch variability was significant only in its characterizing speakers of the third CA decade to a greater degree than those of the fourth CA decade. Pitch (high) seemed to be related to younger (CA) speakers. 
Because of the limited number of speakers rated beyond " 0 " and the absence of overall patterns;: no conclusive statements regarding age-related changes in pitch, and its variability, can be made. These results do seem to support the implications of Luchsinger and Arnold (1965). The authors noted a shifting of pitch range, and the direction of that shifting, depend on the type of physiological changes which occur with aging. If the cords thicken, lower pitches may be expected; whereas, in the case of atrophic changes, higher frequencies may occur. Based on this explanation, the individual differences and 1ack of general age-related patterns are what would be expected. The varied results of the present study might also explain the disagreement among pitch and aging reports in the literature. Perhaps past conclusions have been based on limited data or numbers of observations. When considering a large sample, as in the present study, the inter-individual differences and general lack of noticeable change were remarkable, more so than any trend suggesting pitch either goes up or down with increases in age. The varied findings in the literature may be dependent upon the particular physiological change(s).

The remaining relationships, indicated by statistical analyses, are interesting mostly in terms of the present investigation. Imprecise consonants was associated with aging, only in terms of PA. Two parameters were inversely related to aging: the results suggest speakers who are 
perceived as being between 40 and 50 years old, have soft and breathy voices. Hyper - and hyponasality have been shown to be characteristic of speakers perceived as being 50-59 years o1d. Four relationships were indicated for speakers grouped in terms of CA only. Fast rate of articulation was associated more with the younger CA decade speakers, than with the older speakers. Slow rate of articulation was not rated beyond "0" for 60-69 CA decade speakers, and was therefore significantly low when the mean rating for that decade was compared to the means of the other three decades. Laryngeal tension and hoarseness were shown to be significantly characteristic of speakers between 50 and 60 years CA.

The relationships described in the above paragraph are specific and were indicated statistically because of ratings on only a small number of speakers. These factors preclude making conclusive comments. Interpretation of such findings is left to further investigation in future studies.

In comparing the present findings to Ryan's (1971) results, voice tremor is the only parameter which is related to aging, in both males and females. Ryan did not find vocal fry to be a predictor of aging. The other parameters he found to be related to perceived aging in males were laryngeal tension, air loss, imprecise consonants, and slow rate of articulation. The present investigation did not demonstrate, conclusively, such relationships between ratings on these parameters and aging, in females. 
Does the Inter-Judge Agreoment on Age

Estimation Vary with Increases in the

Subjects ' Chronological Ages?

The statistical analysis, of the relationship between aging and agreement in 1isteners' age estimation, indicated inter-judge agreement on age estimation does not improve, significantly, as subjects increase in age. This suggests there are no more definitive cues, which are widely accepted as being associated with the older female speaker, than there are for younger speakers. The moderate correlation between CA and PA does suggest, however, there are perceptual cues in female voices which are generally associated with age. Whether or not these cues are the same ones which were analyzed in this study is open to question.

Further interpretation of the results would seem purely speculative, because of the many uncontrolled factors which influence human perception. One source of discussion of some characteristics of perceptual behavior was provided by Helson (1964). These characteristics include time-order and space-order "errors," fatigue, central tendency, and the development of internal standards. All of these seem relevant to the procedural aspects and listening tasks in the present investigation. With this in mind, the consistent prediction of perceived age, on the basis of the perception of vocal parameters alone, seems to be an extremely difficult task. 
In spite of the complex nature of the perceptual task, the present investigation provided evidence of distinct relationships involving the perception of voice parameters and aging in some females. This evidence was particularly convincing for two parameters-voice tremor and vocal fry. 


\section{CHAPTER V}

\section{SUMMARY AND IMPLICATIONS}

\section{SUMMARY}

An interest in understanding the aging processes, as they relate to voice, has prompted research investigating physiological, acoustical, and perceptual attributes of the aging vocal mechanism. Recently, it has been demonstrated that perceptual parameters, in older male voices, differentiate speakers according to age estimations, as determined by a group of listeners.

The purpose of this study was to determine the perceptual characteristics of the female voice which are associated with perceived age, as contrasted to chronological age.

The present investigation sought answers to the following questions:

1. By decades, to what degree do selected perceptual parameters characterize the voices of women from 40 to 80 years in perceived age?

2. By decades, to what degree do selected perceptual parameters characterize the voices of women from 40 to 80 years in chronological age?

3. Secondarily, does the inter-judge agreement on age estimation vary with increases in the subjects' 
chronological ages?

The voices of 60 female subjects, ranging from 40 thnough 80 years of age, were recorded. In Part I of the study, 11 college students listened to voice samples and estimated the speakers' ages. In Part II, 4 trained judges rated the voices, according to the presence of 18 selected vocal parameters.

For each voice sample, the mean perceived age (PA) and standard deviation were determined, based on the 11 age estimations. The ratings of the vocal parameters were analyzed according to $\mathrm{PA}$ and $\mathrm{CA}$ decade groupings. An analysis of variance and a posteriori tests of pairwise differences were used to determine the significance of relationships between the perceptual parameter ratings and the PA or CA decades. The relationship between aging and inter-judge agreement on age estimation was assessed using a Pearson $r$ coefficient of correlation.

In general, when classified by PA and CA decades, the voices were normal, with an emphasis on a lack of characteristics which might be age-related. Voice tremor and vocal fry were found to be the primary indicators of perceived and chronological aging, by decade.

Five other parameters, which were statistically shown to relate in some way with $\mathrm{PA}$ and $\mathrm{CA}$ groups, were as follows: pitch (high), pitch (low), excessive pitch variability, reduced pitch variability, and breathy. Four parameters were 
characteristic of specific PA decades, only: loudness (soft), imprecise consonants, hypernasal, and hyponasal. The four parameters which were shown to be characteristic of CA decades, only, were fast rate of articulation, slow rate of articulation, laryngeal tension, and hoarseness. For these thirteen parameters, results were interpreted as indicative of inter-individual differences, or as unique to this particular group of women.

The inter-judge agreement on age estimation was not significantly related to chronological aging. This suggests older female voices are not characterized by age-related cues which are more definite than those associated with younger speakers.

\section{IMP L ICAT IONS}

\section{C1inical}

The findings in this study provide information which may be useful in the diagnosis of voice disorder cases among older women. First of a11, it has been shown that in judging women's voices, from 40 through 80 years PA or CA, most listeners perceived the majority of the samples as "normal." Where deviant parameters were perceived, they were rated as "noticeable," or "mildly clinical." There seems to be little evidence for assuming a disordered voice in an older female is simply "a sign of growing old." In diagnosis, then, a voice specialist should consider possible organic pathology 
and abuse or misuse of the vocal mechanism.

The exceptions to this clinical approach would be in cases where older women's voices are characterized primarily by voice tremor or vocal fry. Current knowledge of the physiological effects of aging on the vocal mechanism, as well as the findings revealed by the present investigation, suggest vocal fry and voice tremor can be expected to increase in magnitude or frequency among voices of older women. In such cases, clinical intervention may not be indicated.

\section{Future Research}

Because of the complex nature of human perception, future studies might focus on the effects of varying the design of the perceptual task. For example, it is possible the order of stimuli presentation affects the 1isteners' judgments of speaker age or severity of disorder. This could be studied by varying the sequence of presentation of a set of voice samples. Changing the duration of judging sessions, or the length of samples, would provide information regarding fatigue effects. The variable of "internal standards" also merits consideration. One way of studying this would be to contrast the responses of a group considered to be somewhat homogeneous (age, sex, academic training, professional background) with the responses of a more heterogeneous group of judges. Another perceptual behavior, the tendency to not judge toward the extremes of a given range, was apparent in the distribution of age estimation responses. In future 
research, this tendency might be avoided by not informing 1isteners of the speakers' age range.

Future researchers might also vary the experimental approach or focus, in terms of acquiring and assessing voice samples. It would be interesting to see if similar results were obtained when requiring subjects to perform tasks other than reading. This might involve recording conversational voice samples. Vocal tasks could also vary with regard to amount of stress placed on the speaker. Testing the limits of vocal performance might more clearly differentiate speakers according to age. Changing the criteria of subject selection, as noted earlier, offers another possibility for future investigation. If a broader range of individual differences were represented, perhaps the data would show a closer agreement on age estimation and more parameters indicative of CA or PA or both. Extending the upper limit of the age range of subjects might also reveal age associated differences not found in the present investigation. Another area of research in women's voices deals with the effects of menopause. By focusing on one characteristic, such as pitch or hoarseness, a researcher could devote more attention to variables associated with menopause.

Finally, the value of a longitudinal study is certainly indicated by the present findings. Because of the variety of vocal characteristics and wide range of normalacy; patterns of vocal change, associated with aging, may go un- 
noticed in a cross-sectional study. A longitudinal study would provide valuable supplemental information. 


\section{LIST OF REFERENCES}

BACH, A.C., LEDERER, F.L., and DINOLT, R., Senile Changes in the Laryngeal Musculature. Archs. Otolary., 34, 47-56 (1941).

BOONE, D.R., The Voice and Voice Therapy (2nd edition). Englewood Cliffs, New Jersey: Prentice-Ha11, Inc. $(1977)$.

BRACKETT, I.P., Parameters of Voice Quality. In L.E. Travis (Ed.), Handbook of Speech Pathology and Audiology. Englewood Cliffs, New Jersey: Prentice-Ha11, Inc., - $441-463$ (1971).

COOPER,. M., Voice Problems of the Geriatric Patient. Geriatrics, 25, 107-110 (1970).

DARLEY, F.L., ARONSON, A.B., and BROWN, J.R., Differential Diagnostic Patterns of Dysarthria. J. Speech Hearing Res., 12, 246-269 (1969).

DENES, P., and PINSON, E., The Speech Chain. Murray Hi11, New Jersey: Bell Telephone Laboratories (1963).

DORLAND, W.A.N., I11ustrated Medical Dictionary (25th edition). Philadelphia: W. B. Saunders (1974).

ENDRES, W., BAMBACH, W., and FLOSSER, G., Voice Spectograms as a Function of Age, Voice Disguise, and Voice Imitation. J.Acoust. Soc. Amer., 49, 1842-1848 (1971).

FAIRBANKS, G., Voice and Articulation Drillbook (2nd edition). New York: Harper and Row (1960).

GREENE, M.C.L., The Voice and Its Disorders (2nd edition). Philadelphia: J. B. Lippincott (1967).

GUILFORD, J.P., Fundamental Statistics in Psychology and Education (3rd edition). New York: McGraw-Hil1 Book Company, Inc. (1956).

HELSON, H., Adaptation-Level Theory. New York: Harper and Row (1964).

KIRK, R.E., Experimental Design: Procedures for the Behavioral Sciences. Belmont, California: Brooks/Cole Publishing Company (1968). 
KOFLER, K., cited by R. Luchsinger and G.E. Arnold, VoiceSpeech-Language Clinical Communicology: Its Physiology and Pathology. Belmont, California: Wadsworth Publishing Company, Inc. (1965).

LINKE, C.E., A Study of Pitch Characteristics of Female Voices and Their Relationship to Vocal Effectiveness. Ph.D. dissertation, State University of Iowa (1953), Published in Folia phoniat., 25, 173-185 (1973).

LLOYD, W.H., Value of the Voice in the Diagnosis of Myxedema in the Elderly. Brit. Med. J., 5131, 1208-1211 (1959).

LUCHSINGER, R., and ARNOLD, G.E., Voice-Speech-Language Clinical Communicology: Its Physiology and Pathology. Belmont, California: Wadsworth Publishing Company, Inc. (1965).

MASORO, E., Other Physiologic Changes with Age. In A.M. Ostfeld and D.C. Gibson (Eds.), Epidemiology of Aging. Washington, D.C.: U.S. Government Printing Office, $137-155(1972)$.

McGLONE, R.E., and HOLLIEN, H., Vocal Pitch Characteristics of Aged Women. J. Speech Hearing Res., 6, 164-170 (1963).

MOORE, G.P., Voice Disorders Organically Based. In L.E. Travis (Ed.), Handbook of Speech Pathology and Audiology. Englewood Cliffs, New Jersey: Prentice-Ha11, Inc., $535-569$ (1971).

MYSAK, E.D., Pitch and Duration Characteristics of 01der Males. J. Speech Hearing Res., 2, 46-54 (1959).

NEUGARTEN, B.L., and KRAINES, R.J., Menopausal Symptoms in Women of Various Ages. In L. Gitman (Ed.), Endocrines and Aging. Springfield, Illinois: Charles C. Thomas Publishers, 218-230 (1967).

PERKINS, W.H., Vocal Function: A Behavioral Analysis. In L.E. Travis (Ed.), Handbook of Speech Pathology and Audiology. Englewood Cliffs, New Jersey: PrenticeHa11, Inc., 481-503 (1971).

PERKINS, W.H., Speech Pathology: An Applied Behavioral Science (2nd edition). Saint Louis, Missouri: The C.V. Mosby Company (1977).

PONTOPPIDAN, H., and BEECHER, H.K., Progressive LOSS of Protective Reflexes in the Airway with the Advance of Age. J. Am. Medica1 Asso., 174, 77-81 (1960). 
PRESSMAN, J.J., and KELEMAN, G., Physiology of the Larynx. Physio1. Rev., 35, 506-554 (1955).

PTACEK, P., and SANDER, E.K., Age Recognition From Voice. J. Speech Hearing Res., 9, 273-277 (1966).

PTACEK, P., SANDER, E.K., MALONEY, W.H., and JACKSON, C.C.R., Phonatory and Related Changes with Advanced Age. J. Speech Hearing Res., 9, 353-360 (1966).

RYAN, W.J., Perceptual and Acoustic Correlates of Aging in the Male Voice. Ph.D. dissertation, Purdue University (1971).

SAXMAN, J.H., and BURK, K.W., Speaking Fundamental Frequency Characteristics of Middle-Aged Females. Folia phoniat., $19,167-172$ (1967).

SEGRE, R., Senescence of the Voice. EENT Mon., 50, 223-233 (1971).

SHERIDAN, J., Restoring Speech and Language Skills. Geriatrics, 31, 83-86 (1976)

SHIPP, T. and HOLLIEN, H., Perception of the Aging Male Voice. J. Speech Hearing Res., 12, 703-710 (1969).

TERRACCI, J. and AZIMAR, R., cited by R. Luchsinger and G.E. Arnold, Voice-Speech-Language Clinical Communicology: Its Physiology and Pathology. Belmont, California: Wadsworth Publishing Company, Inc. (1965).

WALKER, H.M. and LEV, J., Elementary Statistical Methods (3rd edition). New York: Holt, Rinehart and Winston, Inc. (1969).

WINER, B.J., Statistical Principles in Experimental Design (2nd edition). New York: McGraw-Hill Book Company (1971).

WILSON, F.B., Voice Disorders in Children, a training tape produced under Grant No. OEG-0-70-23-(607) from the United States Office of Education (1971).

ZEMLIN, W.R., Speech and Hearing Science Anatomy and Physiology. Englewood Cliffs, New Jersey: Prentice-Ha11, Inc. (1968). 


\section{APPENDIX A}

\section{QUESTIONNAIRE USED FOR SUBJECT SELECTION AND PERSONAL INTERVIEW}

Name:

Age :
Address :

Phone Number:

1. Have you ever had formal voice or speech training (or therapy)?

Yes No

If so, please describe briefly.

2. Have you ever had any physical problems which affected your speech or speaking voice?

Yes No

If so, please describe briefly.

3. Are you presently experiencing physical problems which might affect your speech or speaking voice?

Yes No

If so, please describe briefly.

4. Are you now taking, or have you ever taken, hormone medication?

Yes No

If so, please describe the kind of medication. Note also the approximate dates of when you began and stopped taking the medication. 
5. When did your menopause begin?

Age

Have not experienced menopause

Do not know 


\section{APPENDIX B}

\section{TABLE V}

CHRONOLOGICAL AGE (CA), MEAN PERCEIVED AGE (PA), AND STANDARD DEVIATION OF PERCEIVED AGE (SD)

FOR 60 SPEAKERS, EXPRESSED IN YEARS

\begin{tabular}{lll|lll}
\hline CA & PA & SD & CA & PA & SD \\
\hline 40 & 47.81 & 7.73 & 60 & 65.09 & 6.37 \\
40 & 51.72 & 5.72 & 60 & 70.00 & 5.91 \\
42 & 44.54 & 4.52 & 61 & 55.63 & 5.42 \\
42 & 69.09 & 6.12 & 62 & 47.09 & 4.63 \\
43 & 50.90 & 7.71 & 63 & 58.63 & 6.59 \\
43 & 47.36 & 5.53 & 63 & 56.90 & 7.02 \\
45 & 44.00 & 4.04 & 64 & 61.09 & 7.98 \\
47 & 57.36 & 6.36 & 65 & 69.81 & 4.97 \\
47 & 55.45 & 8.65 & 66 & 62.00 & 6.73 \\
48 & 60.18 & 6.47 & 67 & 52.09 & 6.28 \\
48 & 60.09 & 6.17 & 67 & 64.81 & 10.40 \\
48 & 54.81 & 6.14 & 68 & 57.00 & 8.43 \\
49 & 51.00 & 8.03 & 68 & 62.36 & 5.78 \\
49 & 55.18 & 9.68 & 68 & 78.00 & 2.04 \\
49 & 53.36 & 7.92 & 69 & 61.27 & 8.27 \\
50 & 51.72 & 9.40 & 71 & 64.09 & 4.20 \\
50 & 66.45 & 6.59 & 72 & 65.90 & 8.17 \\
52 & 58.81 & 6.52 & 73 & 69.00 & 5.34 \\
53 & 46.09 & 7.16 & 73 & 64.27 & 5.53 \\
53 & 45.54 & 7.24 & 73 & 66.81 & 6.04 \\
53 & 59.09 & 6.77 & 74 & 69.00 & 6.24 \\
53 & 67.81 & 3.40 & 74 & 65.90 & 5.61 \\
54 & 56.00 & 8.19 & 75 & 65.54 & 8.46 \\
56 & 67.00 & 7.89 & 75 & 68.27 & 5.71 \\
56 & 45.90 & 7.80 & 75 & 68.63 & 5.88 \\
57 & 53.09 & 5.59 & 75 & 70.90 & 5.02 \\
57 & 52.54 & 7.76 & 76 & 66.36 & 5.74 \\
57 & 64.45 & 7.99 & 76 & 57.90 & 7.66 \\
58 & 46.18 & 7.12 & 76 & 70.36 & 5.25 \\
59 & 75.54 & 4.32 & 78 & 74.90 & 4.96 \\
& & & & & \\
\hline & & & & &
\end{tabular}




\section{APPENDIX C}

VOICE PROFILE FORM

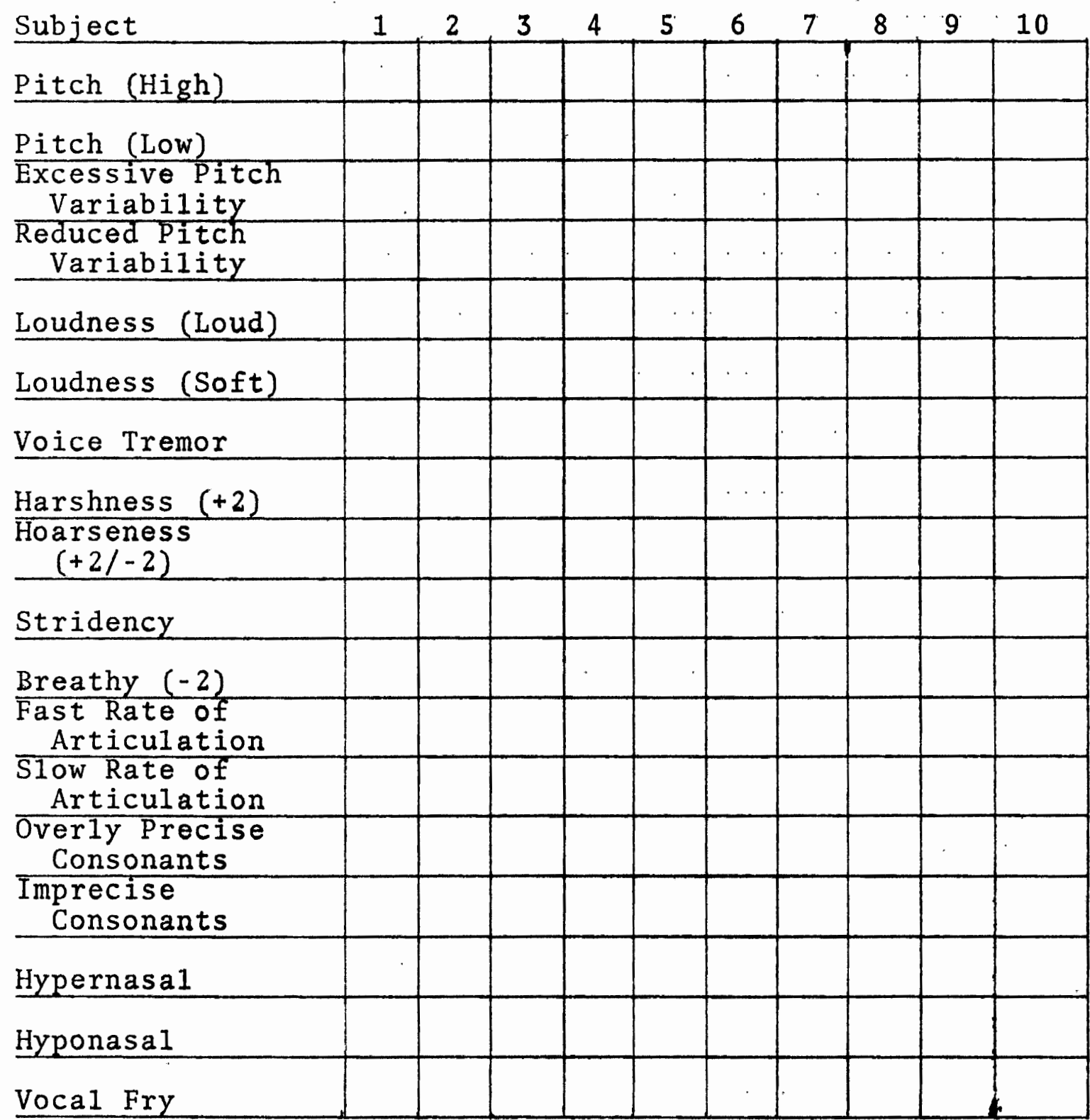


APPENDIX D

DESCRIPTIONS OF THE PERCEPTUAL PARAMETERS

AND VOICE RATING SCALE

\section{Perceptual Parameters}

Most of the parameters to be judged were selected from published research investigating age-related vocal characteristics. Loudness (loud), fast rate of articulation, and overly precise consonants were added to complete the pattern of binary choices between successive pairs. The last three parameters, hypernasality, hyponasality, and vocal fry, were added during the first training session. The judges and experimenter discussed the prevalence of these characteristics among the voice samples, and their possible association with aging: As a result, the following list of perceptual parameters was compiled for the purposes of this study. Each listener received a similar copy, entitled "Rating Guidelines," which listed the parameters, definitions and rating scale. The parameters and their descriptions were presented to the listeners in this order to facilitate judgments, i.e., the parameters pertaining to a particular dimension of voice (such as pitch) were grouped together.

Pitch (high)--The average pitch is consistently higher than customary for a person of similar age and sex in this 
culture (Moore, 1971).

Pitch (10w)--The average pitch is consistently lower than customary for a person of similar age and sex in this culture (Moore, 1971).

Excessive pitch variability--Pitch changes do not fit the meaning being expressed (Moore, 1971); that is, the intonational pitch changes are unpredictable and inappropriate, according to cultural expectations. Reduced pitch variability--Pitch changes do not fit the meaning being expressed (Moore, 1971); that is, the intonational pitch changes are restricted, or limited to one tone, as in monotone.

Loudness (loud)--The voice is too loud in relation to the requirements of the place and circumstances (Moore, 1971). In terms of typical voice production, Perkins described deviation from optimum loudness as follows:

The louder the voice, the greater the constriction and the greater the vocal effort. Conversely, the greater the constriction, the greater the vocal effort required to maintain a given level of loudness (Perkins, 1977).

Loudness (soft)--The voice is not loud enough to adequately meet communicative needs (Moore, 1971).

Voice tremor--Irregular control of vocal effort may be heard as "tremor" in the resulting pitch and loudness effects.(Perkins, 1977); sporadic intensity and pitch changes (Brackett, 1971). 
Harshness--A perceived phonatory defect attributable to deviations from optimum production of the following vocal dimensions: pitch (low), constriction (high), focus (unbalanced, focused in the mouth), effort (high), smoothness (rough) (Perkins, 1977).

Hoarseness--A perceived phonatory defect attributable to deviations from optimum production of the following vocal dimensions: pitch (low), voicing (breathy), smoothness (rough) (Perkins, 1977).

Stridency--A perceived phonatory defect attributable to deviations from optimum production of the following vocal dimensions: pitch (high), loudness (high), constriction (high), focus (unbalanced, focused in the mouth), effort (high) (Perkins, 1977).

Breathy--"A combination of vocal fold sound and whisper noise produced by turbulent air" (Moore, 1971). Fast rate of articulation--Usually a result of a noticeable reduction in vowel or syllable duration throughout an individual speech sample.

Slow rate of articulation--Usually a result of a noticeable prolongation in vowel or syllable duration throughout an individual speech sample (Ryan, 1971).

Overly precise consonants--Consonant sounds are produced in an extremely exacting manner, so as to seem unnatural, according to cultural expectations.

Imprecise consonants--Consonant sounds lack precision. 
They show slurring, inadequate sharpness, distortions, and lack of crispness. There may be clumsiness in going from one sound to another (Darley, Aronson, and Brown, 1969).

Hypernasality--Vowel sounds are perceived as resonated in the nasal cavity, to an undesirable and excessive degree (Boone, 1977).

Hyponasality--A noticeable lack of nasal resonance is perceived during the production of the three nasalized phonemes $(/ \mathrm{m} /, / \mathrm{n} /$, and $/ \mathrm{g} /$ ) and vowels (Boone, 1977). Vocal fry--Phonation is perceived as low pitched, "bubbling," and "cracking" (Boone, 1977).

\section{Voice Rating Scale}

0 --Not characteristic of the voice being judged. 1--A noticeable parameter, yet within normal range. 2--A parameter which would be considered minimally clinical; mild.

3--A parameter which calls attention to the voice as definitely deviating from the ideal; moderate. 4--A dominant and extremely distracting parameter contributing to the perceived deviancy; severe. 
APPENDIX E

PROCEDURES FOR TRAINING LISTENERS IN PART II

Recordings were made of 20 females whose chronological ages ranged from 40 to 80 years. These subjects' recordings were used only for the training sessions. The voice samples were randomly ordered and re-recorded on a training tape. Each recording was dubbed twice. A training test tape was prepared in the same manner, using the remaining 10 recordings. These 10 recordings were randomized again and rerecorded, for the second part of the training test tape.

A "Rating Guidelines" sheet was given to each listener. This consisted of a 1 ist of the parameters to be judged, their definitions, and a description of the rating scale (Appendix D). Each listener also received a "Voice Profile Form" for recording ratings of the perceptual parameters (Appendix C) .

The following instructions were read to the group:

You are participating in a study investigating the perceptual characteristics of voice in women. Please refer to the sheet with the heading, "Rating Guidelines." The parameters listed are those which you are to rate for each speaker. Read the list and definitions. When everyone has finished reading, we will discuss your questions.

Now read the description of the rating scale which follows the list of parameter definitions. 
As you listen to a speaker, you are to record numerical ratings for each of the 18 parameters. Only the whole numbers from 0 through 4 may be used. Are there any questions?

The other form you received is the Voice Profile rating sheet. In the row across the top are numbers referring to the recordings you will hear. Prior to each speaker's recording, the number of the sample will be read. Make sure you record your ratings in the column corresponding to that number. The parameters are listed in the column on the far left.

As you listen to the adult, female speaker, rate each of the listed vocal parameters, using the five-point rating scale. The speaker will be reading the first paragraph of the "Rainbow Passage." You will hear two successive readings for each speaker. During this training session, we will discuss your ratings, immediately following each of the first six voice samples. You will be asked to orally report your ratings. The experimenter will record responses on a voice profile form. We then will discuss your ratings and any questions you might have concerning this procedure. Listeners, who vary more than one interval point from the group median, should adjust their ratings to more closely coincide with the group ratings. The remaining four samples will be followed by oral rating reports and computations of group medians, only. This will provide you with feedback so you may see how you do when judging more independently.

The tape was played through a high fidelity Ampex PreAmplifier system in a college classroom. After the listeners had rated the 10 recordings, they took a five minute break. The training test tape was played then, without interruption. Listeners recorded ratings on new voice profile forms. After a 15 minute break, the second part of the training test tape was played. The listeners were not told they previously had rated the voices. New voice profile forms were used. 
The following day, another training session (B) was held. The judges reviewed their first and second ratings for each of the 10 recordings on the training test tape, while listening to the tape. The experimenter then led a discussion on the nature of the rating task, rating scale, and some of the terminology. The second part of the training test tape was played, with listeners recording ratings on voice profile forms. Following a 15 minute break, the first part of the training test tape was played and ratings were recorded.

For each judge a percentage of internal agreement was calculated, based on initial and second ratings of the 10 voices. Listed in the order of the respective training sessions ( $A$ and $B$ ), the individual percentages of agreement were as follows: Judge 1--0.82, 0.86; Judge 2--0.82, 0.87; Judge 3--0.82, 0.85; Judge 4--0.79, 0.90. The overa11 intrajudge agreements were 0.81 and 0.87 , for training sessions $A$ and $B$, respectively. The first training session interjudge agreement was 0.88 . After the second training session, the inter-judge agreement was 0.90 percent. 


\section{APPENDIX F}

TABLE VI

ANALYSIS OF VARIANCE FOR VOCAL FRY

\section{Subjects Grouped by PA}

Source of

Variation

SS

df

MS

F

Between Judges

0.311

3

Within Judges

0.931

12

Decades 0.819

3

$0.27322 .8 * *$

Residual 0.112

9

0.012

Total

1.242

Subjects Grouped by CA

Source of

Variation SS

df

MS

F

Between Judges

0.279

3

Within Judges

2.194

12

Decades 2.122

3

$0.707388 .4 * *$

Residua1 0.072

9

0.0080

Total

15

$$
* * F \quad .99(3.9)=6.99
$$

